\title{
A BOUNDEDNESS THEOREM ON HIGHER DIMENSIONAL HILL EQUATIONS
}

\author{
XIAO-SONG YANG
}

Abstract. We present in this note some sufficient conditions on boundedness of solutions to higher dimensional Hill equations.

Mathematics subject classification (1991): 34D05.

Key words and phrases: Hill equation, boundedness of solutions.

\section{REFERENCES}

[1] R. Bellman, Stability of diferential equations, McGraw-Hill, New York, 1953.

[2] J. M. BownDS, Stability implication on the asymptotic behavior of second order diferential equations, Proc. Amer. Math. Soc. 39 (1973), 169-172.

[3] S. Gollor, D. Hulin AND J. Lafontaine, Riemannian Geometry, Springer-Verlag, Berlin Heidelberg, 1987.

[4] J. K. HALE, Ordinary differential equations, Wiley-interscience, New York, 1969.

[5] M. Pettini and R. Valdettaro, On the Riemannian description of chaotic instability in Hamiltonian dynamics, Chaos 4 (1995), 646-652. 